Kanban Eletrônico para otimização de processos internos e externos da cadeia de suprimentos: aplicação em uma empresa do setor automotivo

\title{
Electronic Kanban for the optimization of internal and external processes in the supply chain: application in an automotive industry company
}

Gisele Beheregaray Argollo Meira ${ }^{1}$ - Universidade Federal do Rio Grande do Sul- Escola de Engenharia

Marcelo Nogueira Cortimiglia ${ }^{2}$ - Universidade Federal do Rio Grande do Sul- Escola de Engenharia

Bernardo Henrique Leso ${ }^{3}$ - Universidade Federal do Rio Grande do Sul- Escola de Engenharia

\section{RESUMO}

A presente pesquisa descreve a concepção, implantação e avaliação crítica de uma solução de Kanban Eletrônico em uma indústria do setor automotivo. Este setor possui muita dificuldade em integrar processos de abastecimento entre clientes e fornecedores, principalmente em consequência do efeito chicote característico desta indústria. Tendo isto em vista, além de uma série de outras dificuldades enfrentadas internamente na empresa em estudo que comprometem a eficiência e confiabilidade do processo, propôs-se a substituição do sistema tradicional de abastecimento de materiais por cartões Kanban pelo Kanban Eletrônico. Os resultados foram apresentados utilizando um método que separa a intervenção na empresa da pesquisa acadêmica, de forma que os dados coletados durante o projeto na empresa foram registrados e serviram de input para que se estruturasse e apresentasse os resultados da pesquisa. Assim, além de estudar o estado atual e propor uma projeção para o futuro, houve descrição do processo de implantação e exploração das dificuldades associadas. Ademais, apresenta-se uma análise crítica sobre os ganhos que o sistema proporcionou e ainda pode proporcionar à empresa.

Palavras-Chave: Kanban Eletrônico. Código de Barras. Implantação. Setor Automotivo. Cadeia de Suprimentos.
Editor Responsável: Prof. Dr. Hermes Moretti Ribeiro da Silva

\section{ABSTRACT}

This paper describes the design, implementation and critical evaluation of an Electronic Kanban solution in the automotive industry. This sector still experiences difficulties integrating the supply processes between customers and suppliers, mainly as a consequence of the typical bullwip effect. With this in mind, as well as a number of other difficulties faced internally by the studied company that contributed to compromised efficiency and reliability of the process, it was proposed that the traditional Kanban Cards should be replaced by the Electronic Kanban. The results are presented using a method that sought to distinguish between practical intervention conducted within company and academic research, whilst highlighting the way in which the data collected during the intervention was used as an input to structure and inform the results of the study. Therefore, in addition to studying the current state and proposing a future state, a description of the implementation process was presented and the associated difficulties were explored. Furthermore, a critical analysis of the gains that the system afforded the company was presented and those it may continue to offer in the future.

Keywords: Electronic Kanban. Bar code. Implementation. Automotive Sector. Supply Chain.

1. Av. Osvaldo Aranha DEPROT/PPGEP, 99, 50 andar, Porto Alegre, RS, 90035-190, giargollo@hotmail.com; 2. cortimiglia@ producao.ufrgs.br; 3. bernardoleso@gmail.com

MEIRA, G.B.A.; CORTIMIGLIA, M.N.; LESO, B.H. Kanban Eletrônico para otimização de processos internos e externos da cadeia de suprimentos: aplicação em uma empresa do setor automotivo. GEPROS. Gestão da Produção, Operações e Sistemas, v. 14, n. 5, p. $01-22,2019$. 
Kanban Eletrônico para otimização de processos internos e externos da cadeia de suprimentos: aplicação em uma empresa do setor automotivo

\section{INTRODUÇÃO}

Na busca das empresas por vantagem competitiva, a tecnologia da informação (TI) tem o potencial de otimizar processos e gerar valor para o negócio. Esta visão da TI como ferramenta estratégica competitiva é sustentada por diversos autores (MAÇADA et al., 2007; FIALHO, 2001), sendo que se justifica pelo fato de que a tecnologia apoia operações existentes e permite o desenvolvimento de novas estratégias de negócio (LAURINDO et al., 2001).

Para Gunasekaran e Ngai (2004), o principal paradigma do século XXI para que empresas se tornem competitivas é a efetiva gestão da cadeia de suprimentos, o que é somente possível através da utilização de TI. Lambert (2000) indica que uma gestão efetiva se faz possível graças à integração de processos-chave da empresa através dos diferentes membros da cadeia. Prajogo e Olhager (2012) evidenciaram que a integração da cadeia de suprimentos é alcançada pela integração das informações aliada à integração do fluxo de materiais, esta última igualmente chamada de logística integrada.

Branski e Laurindo (2013) classificam as tecnologias da informação aplicadas à logística integrada em três categorias: aplicativos, comunicação e tecnologias embarcadas. A primeira se refere às ferramentas como o enterprise resource planning (ERP), warehouse manegement system (WMS) e business intelligence (BI). A segunda, de comunicação, inclui coletores de dados, terminais portáteis, electronic data interchange (EDI) e ferramentas WEB. A terceira inclui rastreamento, roteirização e otimização de carga.

O Kanban Eletrônico é um sistema que permite integrar tecnologias de comunicação e de aplicativos, permitindo a visibilidade das operações de logística integrada. Através do uso de coletores de dados, terminais portáteis, integração com o ERP e EDI, o sistema comporta a automação dos processos de movimentação de materiais, sendo que o ganho mais considerável é o aumento do giro de estoques (AMANN, 2009). Porém, apesar das vantagens conhecidas em relação ao método tradicional de cartões, existem poucas pesquisas científicas que realmente descrevam o desenvolvimento, implantação e operacionalização do sistema (KOURI et al., 2008).

Desta forma, o presente artigo tem como objetivo a concepção, implementação e avaliação dos resultados de uma solução de Kanban Eletrônico com potencial para integrar e 
Kanban Eletrônico para otimização de processos internos e externos da cadeia de suprimentos: aplicação em uma empresa do setor automotivo

otimizar os processos logísticos de movimentação de materiais e o fluxo de informações através da cadeia de suprimentos. O trabalho é resultado de uma pesquisa-ação em uma empresa do setor automotivo e, além de descrever a solução, características e limitações, são apresentados os resultados financeiros gerados pela integração proposta.

O trabalho está estruturado em seis seções principais: referencial teórico com a exposição dos conceitos a serem abordados ao longo do trabalho e construção de base teórica que sustente os resultados; descrição dos procedimentos metodológicos selecionados; a seção dos resultados do estudo, seguida da discussão e conclusão.

\section{REFERENCIAL TEÓRICO}

Inicialmente, são apresentados e discutidos tópicos referentes à Gestão Logística e Gestão da Cadeia de Suprimentos, além de suas características quando inseridos na conjuntura da indústria automotiva. Em seguida, é dada a definição de Sistemas de Informação e suas diferentes classificações e, por fim, ambos os conceitos são relacionados através da exposição dos Sistemas de Informação orientados para a cadeia de suprimentos.

\subsection{Gestão Logística e Gestão da Cadeia de Suprimentos}

Gestão Logística é definida pelo Council of Supply Chain Management Professionals (CSCMP) como sendo a área responsável pelo planejamento, implantação e controle do fluxo e armazenamento de materiais, serviços e informações entre o ponto de origem e o ponto de consumo, de forma a atender de forma satisfatória aos requisitos dos clientes. A gestão logística representa também a função integradora de todas as atividades logísticas entre si e com outras funções da organização, como produção, finanças e tecnologia da informação (CSCMP, 2013).

Um conceito mais amplo no qual a Gestão Logística está inserida é o de Gestão da Cadeia de Suprimentos, ou Supply Chain Management (SCM). Ross (2011) a explica por meio de três diferentes perspectivas: uma tática, uma estratégica e uma tecnológica. A tática considera SCM como sendo uma técnica que busca aperfeiçoar as capacidades operacionais da empresa para buscar oportunidades de redução de custos e aumento da produtividade nas relações com seus clientes e fornecedores. Já pela perspectiva estratégica, a SCM tem como foco influenciar os parceiros da cadeia a realizarem esforços para aprimorar processos logísticos 
Kanban Eletrônico para otimização de processos internos e externos da cadeia de suprimentos: aplicação em uma empresa do setor

automotivo

e estabelecer parcerias com eles a fim de integrar processos relacionados, gerando valor. A perspectiva tecnológica garante às cadeias de suprimentos os meios para concretizar as possibilidades estratégicas previamente desenhadas.

A integração entre os elos da cadeia de suprimento é um dos pontos essenciais para a eficiência do SCM e para indústria automotiva, no entanto, uma das dificuldades neste relacionamento é consequência do efeito chicote (bullwhip effect) (MESQUITA; CASTRO, 2008; ABINAJM et al., 2012). O qual, de acordo com Wang e Disney (2016), caracteriza-se como um fenômeno no qual a variabilidade dos pedidos aumenta na medida em que o pedido avança na cadeia, o que Coelho et al. (2009, p. 01) descrevem como "uma impossibilidade de alinhamento da demanda à oferta". Este fenômeno é reconhecido pela literatura como como um dos principais causadores do desempenho insatisfatório na área de Planejamento e Controle da Produção (PCP) na cadeia automotiva (MESQUITA; CASTRO, 2008), sendo igualmente estudado em modelagem e heurísticas de previsões (DEVIKA et al., 2016; JAIPURIA; MAHAPATRA, 2014; SIRIKASEMSUKA; LUONGB, 2017). Entre as iniciativas para diminuição de incerteza devido ao efeito chicote, estão as mudanças no padrão de reposição de estoques e no investimento em ferramentas de TI (LEE et al., 2004), como por exemplo Internet das Coisas (IoT) baseadas em RFID (LEE. LEE, 2015 p. 431-440). Abordagens clássicas de PCP refletem no controle de reposição de estoques por parte das empresas: o MRP e o Just in Time (JIT).

Slack (2002) explica o conceito de MRP como o sistema empurrado de planejamento e controle das necessidades de recursos, auxiliado por Sistemas de Informação (SI). Já o JIT, de acordo com Slack (2002), refere-se a um método de planejamento e controle puxado da operação que permite uma produção eficaz em termos de custo e o fornecimento de materiais apenas no tempo e local corretos, utilizando o mínimo de recursos para este fim. O controle com cartão Kanban é um método desenvolvido para operacionalizar o JIT, sendo explicado como um sinal utilizado por um estágio-cliente para notificar seu estágio-fornecedor que mais material deve ser suprido.

Existem, de acordo com Slack (2002), três diferentes tipos de Kanban: (i) de movimentação ou transporte - utilizado para informar ao estágio anterior que determinado material pode ser retirado do seu estoque e transferido para um destino pré-determinado; (ii) de 
Kanban Eletrônico para otimização de processos internos e externos da cadeia de suprimentos: aplicação em uma empresa do setor

automotivo

produção - um sinal direcionado a um dado processo produtivo informando que este pode iniciar a produção de certo item de maneira a repor o estoque; e (iii) de fornecedor - cuja finalidade é a de informar ao fornecedor que é preciso realizar o envio de material.

De forma geral, pode-se visualizar no sistema Kanban algumas etapas e processos as quais permitem atribuir oportunidades e consequências para a utilização do sistema em modelos de produção da indústria 4.0 (HOFMANN; RÜSCH, 2016). As etapas e processos são os seguintes: avaliação da demanda; sinal Kanban; disposição da produção; cobrança e entrega; e entrada de mercadorias.

Embora JIT e MRP representem ideias de planejamento da produção bastante distintas, elas podem coexistir formando um sistema híbrido, de acordo com Slack (2002). A maneira como serão combinadas irá depender da complexidade das estruturas do produto, da operação e da cadeia de suprimentos. Em empresas atuais, a implantação tanto das técnicas JIT, quanto do MRP estão relacionadas com o uso de SI.

\subsection{Sistemas de Informação}

O’Brien e Marakas (2010) caracterizam SI como sendo qualquer sistema capaz de coletar, armazenar, transformar e disseminar informações em uma organização. Estes sistemas são viabilizados por uma combinação de recursos incluindo pessoas, hardware, software, redes de comunicação, dados, políticas e procedimentos. Laudon e Laudon (2012) explicam que SI criam valor em uma empresa, visto que podem auxiliar os gestores tanto na tomada de decisão, quanto na coordenação e controle dos processos, análise e visualização de problemas complexos e na criação de novos produtos.

Stair (1998) esclarece que existem diversos tipos de SI, porém dá especial atenção a três grupos: (i) Sistemas de Processamento de Transações (SPT) ou Sistemas de Informação Operacional (SIO), (ii) Sistemas de Informação Gerenciais (SIG) e (iii) Sistemas de Apoio à decisão (SAD) ou Sistemas de Informação Estratégicos (SIE). Laudon e Laudon (2014) tamém incluem nesta lista (iv) os sistemas de inteligência empresarial (BI). Segundo Perottoni (2001) os SPT são de extrema importância para as organizações, visto que dão suporte às operações centrais, gerando aumento da precisão e da confiabilidade dos processos, redução dos custos e do tempo de obtenção das informações. 
Kanban Eletrônico para otimização de processos internos e externos da cadeia de suprimentos: aplicação em uma empresa do setor

automotivo

Tendo como principais entradas os dados gerados pelo SPT, os SIG fornecem informações de rotina para administradores e tomadores de decisão, de maneira que possam controlar, organizar e planejar mais eficientemente as operações (STAIR, 1998). Rezende e Abreu (2006) explicam os SAD como sistemas que fazem uso de dados operacionais e gerenciais processados e transformados em informações estratégicas. Estes sistemas têm por finalidade auxiliar o processo de tomada de decisão dos níveis mais elevados de gerência, oferecendo informações gráficas e amigáveis. É importante destacar que, Segundo Stair (1998), os sistemas SPT, SIG e SAD se sobrepõem muitas vezes, representando sistema que interagem entre si trocando informações (REZENDE; ABREU, 2006).

O Kanban Eletrônico tem a finalidade de controlar inventário e aumentar a eficiência de processos logísticos através da cadeia de suprimentos. Se enquadra na categoria de SPT, pois é utilizado para registrar transações de movimentação de materiais em tempo real. Entre os benefícios trazidos pela implantação deste tipo de sistema, Kouri et al. (2008) destacam a redução de problemas causados em consequência da perda de cartões Kanban, do aumento da velocidade da informação (visto que o cartão não é deslocado na mesma velocidade que um produto é consumido) e da dificuldade de ajuste do sistema de cartões às mudanças no mix de produção (produção de novos cartões e remoção dos obsoletos).

Entre as principais tecnologias utilizadas pelo sistema de Kanban Eletrônico, destacamse o Código de Barras e o Radio Frequence Identification (RFID). Também se destaca que, segundo Hofmann e Rüsch (2016), as tecnologias do setor 4.0 potencializam as capacidades do sistema Kanban em todos os seus aspectos e tem a capacidade de fazer estes sistemas funcionarem muito próximos do que a teoria descreve,

A identificação por código de barras faz parte de um tipo de sistema de autoidentificação desenvolvido com a finalidade de facilitar a coleta e troca de informações logísticas entre os membros da cadeia de suprimentos. Ele se baseia em adaptar códigos legíveis por computador a produtos, embalagens e a veículos de transporte, com a intenção de rastrear e transmitir detalhes destes itens. Estes códigos são lidos por equipamentos que convertem a informação contida no código em informações de interesse (BOWERSOX et al., 2009). RFID, no entanto, refere-se à alocação de um chipe eletronicamente codificado em um item para identificação deste enquanto ele se desloca na cadeia (BOWERSOX et al., 2009). Este chipe 
Kanban Eletrônico para otimização de processos internos e externos da cadeia de suprimentos: aplicação em uma empresa do setor automotivo

irá se comunicar com os leitores por meio de rádio frequência e podem ser tanto ativos quanto passivos, sendo que a diferença está na autonomia do mesmo em relação ao aparelho leitor.

Bowersox et al. (2009) relacionam os conceitos de Logística, Cadeia de Suprimentos e Sistemas de Informação. Para os autores, o foco da Logística está no armazenamento e movimentação de produtos através da cadeia de suprimentos. Desta forma, os Sistemas de Informação voltados para este fim, chamados de Supply Chain Information Systems (SCIS), representariam o fio condutor que une as operações logísticas a um processo integrado.

\section{PROCEDIMENTOS METODOLÓGICOS}

A seção de procedimentos metodológicos se divide em três: (i) descrição do cenário, (ii) caracterização do método de pesquisa e (iii) proposição do método de trabalho.

\subsection{Descrição do cenário}

O cenário de estudo contempla uma unidade brasileira de uma empresa multinacional do setor automotivo, líder mundial na fabricação de soluções e sistemas de transmissão. A sede brasileira da empresa é dividida em cinco diferentes unidades de manufatura, as quais estão distribuídas entre duas plantas. Destas unidades de manufatura, duas fabricam subcomponentes, três fabricam componentes e uma realiza a montagem do produto final. Esta última é abastecida tanto pelos componentes produzidos internamente quanto por componentes oriundos de fornecedores externos.

O presente trabalho foi desenvolvido na Unidade de Manufatura de Montagem (UMM) da empresa, abordando a maneira como produtos comprados são abastecidos junto às células, para atender à produção de itens correntes. Nesta unidade, são montados atualmente 127 itens, os quais juntos utilizam um total de 192 componentes comprados.

Para seu desenvolvimento, o trabalho contou com o suporte e envolvimento das áreas de TI e de supply chain da empresa. A área de supply chain é composta pelas subáreas de Logística, Almoxarifado, Expedição, Planejamento e Controle da Produção e Compras, sendo que a Logística e o Almoxarifado são os setores com mais potencial de impacto pelas mudanças.

\subsection{Caracterização do método de pesquisa}


Kanban Eletrônico para otimização de processos internos e externos da cadeia de suprimentos: aplicação em uma empresa do setor

automotivo

A pesquisa tem natureza aplicada, o que, segundo Bickman e Rog (2008), caracteriza as pesquisas que utilizam metodologia cientifica para coletar informações e solucionar um problema. Quanto aos objetivos, trata-se de uma pesquisa exploratória, pois visa, conforme Gil (2002), à aproximação com o assunto estudado, de maneira a torná-lo mais explícito ou permitir a formulação de hipóteses.

Em relação aos procedimentos, o método da pesquisa se caracteriza como pesquisaação, um conceito de pesquisa cuja principal dimensão construtiva é a ação, permitindo a coexistência da reflexão sobre a investigação teórica e a prática (MIRANDA; RESENDE, 2006). Segundo Mello et al (2012), é uma abordagem na qual se busca entender o fenômeno através da sua observação, interpretação e descrição. A pesquisa-ação é oportuna para a realização do presente trabalho, pois é vastamente utilizada em pesquisas da área de SI, (CHIASSON et al., 2009). Além disso, segundo Mello et al. (2012), é uma estratégia de pesquisa adequada para a área de engenharia de produção por se caracterizar por intervenções que visam o diagnóstico de problemas, proposições de melhorias e transformação de realidades através da implantação de melhorias desenvolvidas em colaboração ativa entre pesquisadores e empresa.

\subsection{Proposição do método trabalho}

Para o desenvolvimento do projeto, foram definidas etapas para dois ciclos da pesquisaação: o ciclo de pesquisa e o ciclo de solução de problema (Figura 1). O ciclo de pesquisa descreve o desenvolvimento com base nas etapas propostas por Mello et al. (2012) e inclui o planejamento da pesquisa, a coleta e análise de dados, o planejamento de ações, a implementação das ações e a avaliação da solução. Já o ciclo de solução de problemas, adaptado da metodologia para o desenvolvimento de um SI, de Rezende e Abreu (2006), defende que a execução do projeto aconteça a partir da sequência das seguintes etapas: estudo preliminar, investigação do sistema atual, desenvolvimento do novo sistema, implantação do novo sistema e sua disponibilização para uso.

A coexistência das etapas de ambos os ciclos caracteriza o presente estudo, o qual tem por objetivo a geração de resultados tanto práticos quanto científicos. Desta forma, propõe-se uma estrutura de cinco etapas para desenvolvimento do trabalho. 
Kanban Eletrônico para otimização de processos internos e externos da cadeia de suprimentos: aplicação em uma empresa do setor

automotivo

A primeira etapa é o estudo preliminar e planejamento da pesquisa e diz respeito à compreensão das funcionalidades, limitações e integrações necessárias para o desenvolvimento e implantação do novo sistema. Etapa realizada na forma de observação-participante na reunião início das atividades do projeto.

Figura 1 - Ciclos de pesquisa

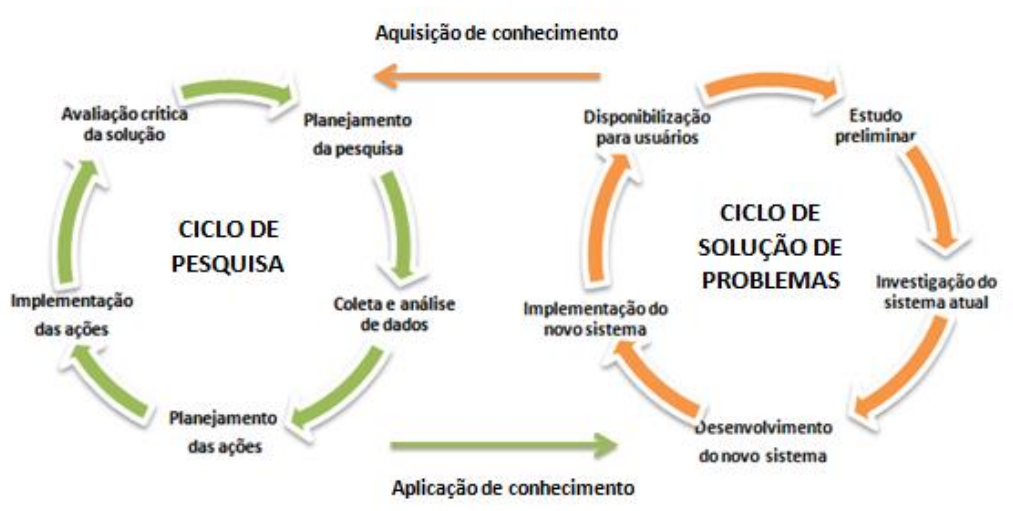

Fonte: Adaptado de Chiasson et al. (2009).

A segunda etapa se refere à investigação do sistema atual e inclui a compreensão do processo, seu desempenho e suas limitações. Para entender os potenciais pontos de melhoria, foram realizadas entrevistas abertas com os usuários do sistema (colaboradores auxiliares das áreas de Logística, Almoxarifado e abastecedores da Montagem) e consultas a fontes documentais da empresa. Além disto, para o mapeamento do processo atual e reconhecimento dos tempos de operação, gargalos, criticidades e opções de melhoria foram executadas cronoanálises e observações-participante.

Sobre a etapa de design e planejamento do novo sistema, terceira etapa, no nível de projeto, a proposta e os principais requisitos do novo sistema foram levantados pelos líderes em conjunto com a equipe de desenvolvimento de sistemas, em reuniões periódicas, para verificação da viabilidade da proposta e realização de ajustes cabíveis. No nível de pesquisa, realizou-se a documentação destas discussões e a representação do sistema a ser implantado.

$\mathrm{Na}$ penúltima etapa - implantação do novo sistema - observa-se o processo de implantação e os testes e treinamentos com os usuários. Como instrumentos de coleta de dado, empregou-se a observação-participante, com registro sistemático de anotações, descrevendo-se 
Kanban Eletrônico para otimização de processos internos e externos da cadeia de suprimentos: aplicação em uma empresa do setor automotivo

as dificuldades e os ajustes que se fizerem necessários para que o sistema funcionasse da maneira prevista.

Por fim, pensou-se a disponibilização do sistema para o uso em dois momentos, o primeiro é uma solução transitória intermediária que visa apresentar resultados incipientes a baixo custo para a promoção da solução completa (segundo momento). Assim, investigaram-se os resultados e a seus impactos na operação. Esta etapa se assemelha à primeira: foram realizadas observações e cronoanálises, além da realização de pesquisa semi estrutarada (entrevistaram-se três auxiliares da Logística, cinco abastecedores da Montagem e três auxiliares do Almoxarifado). Além disto, a etapa inclui uma comparação entre os cenários, apresentando além das melhorias e dificuldades, uma reflexão crítica sobre o sistema implantado.

\section{RESULTADOS}

Inicialmente, é apresentado o macrofluxo do sistema proposto, a seguir é exibida a investigação do sistema inicial, o design do sistema proposto e a descrição da implantação na empresa. A fim de comparar os resultados encontrados nestas três subseções, apresenta-se uma discussão e avaliação de pontos positivos e negativos do novo sistema, além da apresentação dos possíveis pontos de melhoria.

\subsection{Estudo preliminar do sistema proposto}

Propôs-se sistema de Kanban Eletrônico com o intuito de solucionar problemas decorrentes do processo de abastecimento de materiais comprados na fábrica e de prover maior integração interna e externa da cadeia de suprimentos. Entre os principais problemas identificados do sistema de abastecimento por cartões Kanban na empresa, destacam-se os seguintes: (i) falhas no abastecimento decorrente da perda de cartões; (ii) necessidade constante de produção de novos cartões devido às perdas e avarias; (iii) dificuldade de identificação da etapa do processo em que ocorreu alguma falha, consequência da falta de registro das movimentações; (iv) processo ineficiente no Almoxarifado; (v) alto lead time da informação e (vi) alta quantidade de estoque intermediário na fábrica. 
Kanban Eletrônico para otimização de processos internos e externos da cadeia de suprimentos: aplicação em uma empresa do setor

automotivo

Os dois primeiros problemas podem ser apreciados através de alguns dados históricos. O índice médio de perdas por mês de cartões Kanban gira em torno de $13 \%$ do total, o que representa a necessidade de reinserção de aproximadamente 100 cartões por mês no fluxo. Esta atividade demanda três horas de trabalho por mês na produção de novos cartões de um analista da Logística. Em relação ao terceiro problema, as transações dificilmente possuem registro, de forma que é trabalhoso investigar a causa de falhas no abastecimento. Já o problema relacionado ao processo ineficiente do Almoxarifado tem relação com o caráter manual do processo, o que exige a digitação e impressão de todos os pedidos. Por fim, o grande lead time da informação é consequência do tempo entre solicitação dos cartões e o pagamento e é estimado em quatro horas. O resultado deste lead time é o aumento do volume de estoque intermediário, estimado em 300 mil reais.

Para a solução dos problemas é necessário aumentar o nível de integração interna (registrando e centralizando as transações no sistema) e externa, enviando o Kanban de pedidos para fornecedores nacionais. A Figura 2 representa o fluxo de materiais e informações esperado do novo sistema, demonstrando a integração de informações entre os membros da cadeia.

Figura 2 - Fluxo de materiais e informações do novo sistema

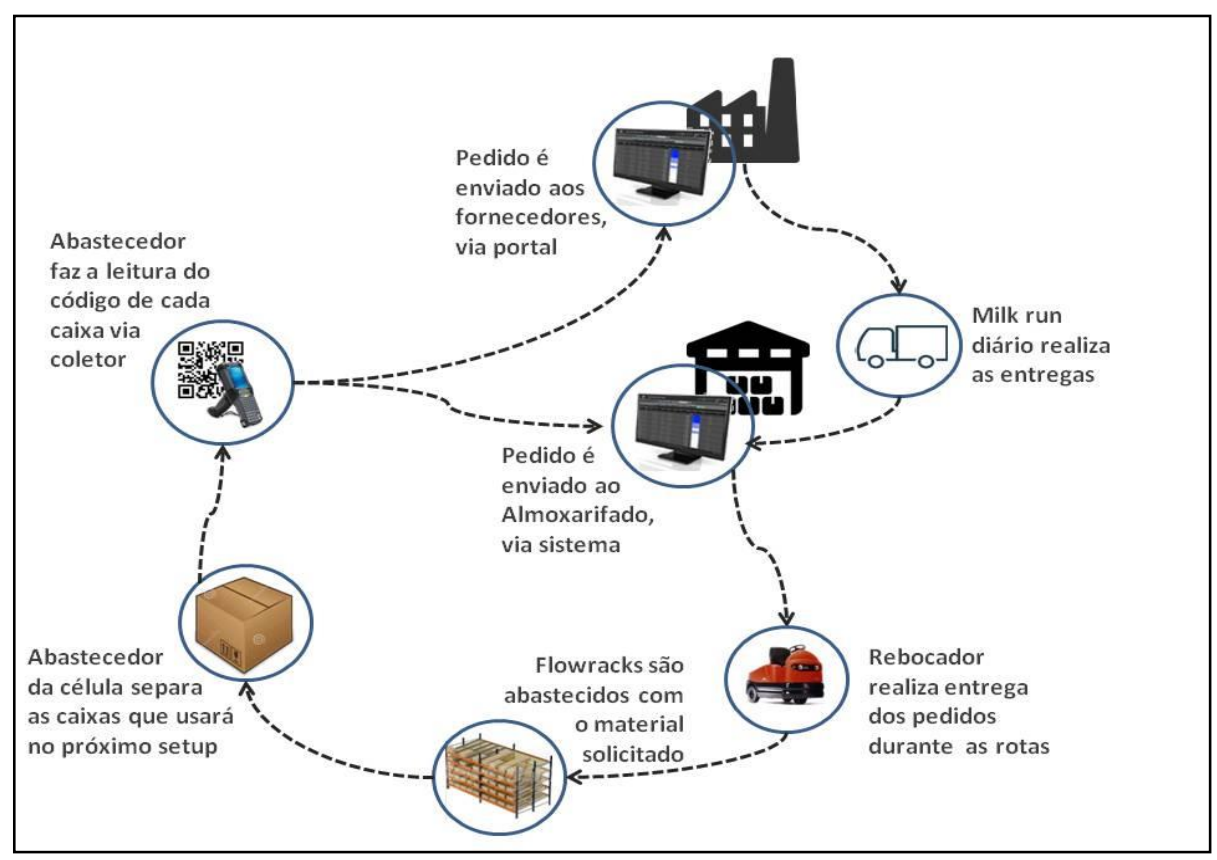

Fonte: Elaborado pelos autores (2019). 
Kanban Eletrônico para otimização de processos internos e externos da cadeia de suprimentos: aplicação em uma empresa do setor automotivo

\subsection{Investigação do Sistema Inicial}

O processo de abastecimento de materiais comprados se mostrou digno de atenção, pois muitas atividades não agregam valor à empresa. O processo tem início com a programação da produção pelo setor de PCP da empresa. Semanalmente, os analistas de demanda recebem via EDI as "carteiras de pedidos" das montadoras que contém informação de demanda da semana seguinte e uma previsão de demanda para as próximas treze semanas. Como as carteiras sofrem variações ao longo das semanas, os analistas de demanda precisam constantemente realizar análises de capacidade e disponibilidade de materiais antes de aceitarem acréscimos às quantidades informadas na carteira anterior. No momento em que uma carteira é aceita, as informações são automaticamente carregadas no sistema. Com base nestes dados, os analistas de materiais executam semanalmente o MRP como forma de definir as quantidades de materiais necessárias nas próximas semanas para atender as necessidades dos clientes. Como resultado do MRP, as necessidades de materiais são encaminhadas aos fornecedores nacionais e internacionais e ficam disponíveis via portal da empresa.

Porém, para alguns fornecedores nacionais, selecionados com base em fatores como proximidade geográfica e volume de materiais comprados, os pedidos não são feitos com base na programação do MRP. Para estes fornecedores, que possuem um caminhão Milk Run exclusivo para efetuar coletas diárias ou com intervalos de um dia, os pedidos são enviados diariamente. Estes pedidos são dimensionados com base em verificações rotineiras do nível de estoque dos produtos no Almoxarifado. A empresa possui atualmente nove fornecedores que se enquadram nesta classificação.

Uma vez que os materiais comprados chegam à empresa, são armazenados no Almoxarifado. Porém, os materiais utilizados por produtos de linha, possuem também um estoque mínimo em supermercados junto às células, estes conhecidos como Flowracks. O cálculo do estoque em Flowracks para cada material comprado se dá pelo somatório da capacidade máxima de cada célula que utiliza o material para a produção de itens de linha, multiplicado pelo OEE (Overall Equipment Effectiveness) de 80\% (meta de eficiência da área de montagem), multiplicado por quatro horas de abastecimento (tempo máximo entre o instante de uma caixa ser retirada do Flowrack e o momento desta caixa ser reabastecida) e dividido 
Kanban Eletrônico para otimização de processos internos e externos da cadeia de suprimentos: aplicação em uma empresa do setor automotivo

pelo número de componentes contidos na caixa enviada pelo fornecedor. Com o dimensionamento mencionado, a empresa possui um estoque em Flowracks estimado em R\$ $302.000,00$.

O processo de movimentação e abastecimento destes materiais na fábrica tem início no Almoxarifado. Durante a separação do material solicitado, o funcionário dispõe um cartão Kanban dentro da caixa com informações sobre o material (descrição e código do material, além do múltiplo da caixa enviada pelo fornecedor). Este material é alocado no carrinho do veículo rebocador a ser transportado pelo auxiliar da Logística o qual, conforme previsto em sua rota, passa pelos pontos de abastecimento da fábrica, onde se encontram os flowracks. Em cada flowrack, o auxiliar de logística aloca as caixas em seus respectivos espaços e recolhe os cartões Kanban devolvidos, correspondentes às caixas já utilizadas. Isto acontece, pois quando o abastecedor da célula da Montagem buscar as caixas de um dado material para uso na produção, ele deve retirar o cartão da caixa e colocá-lo no coletor de cartões para retorno.

Uma vez que o auxiliar logístico conclua sua rota, ele entrega os cartões recolhidos no Almoxarifado para serem transformados em pedidos no sistema. Algum auxiliar ou analista do setor, dependendo da sua disponibilidade no momento, fica responsável por fazer a inclusão manual dos cartões no sistema, sendo que cada cartão representa o pedido de uma caixa daquele material e o tipo de pedido depende do material solicitado. Alguns materiais são demandados de forma automática no sistema através da função "Picking List", porém outros são solicitados via função "Requisição de Material” (RM), manualmente.

Por fim, é impressa uma lista dos materiais que devem ser separados para entrega em virtude dos pedidos oriundos dos cartões. $\mathrm{O}$ auxiliar responsável pela separação recebe esta lista contendo o endereço de cada um dos materiais no armazém, além dos cartões Kanban para serem recolocados no fluxo.

Com vistas a melhor compreender o estado inicial do processo de abastecimento de materiais comprados na fábrica, realizaram-se contagens dos tempos de todas as etapas do processo. Foram realizadas 10 repetições e os tempos médios encontram-se na Tabela 1. 
Kanban Eletrônico para otimização de processos internos e externos da cadeia de suprimentos: aplicação em uma empresa do setor

automotivo

Tabela 1 - Tempos dos processos da Logística e Almoxarifado

\begin{tabular}{lc}
\hline Processo Logística & Tempo \\
\hline Abastecimento do Flowrack e recolhimento de cartões & $00: 16: 32$ \\
Tempo total da rota (incluindo o transporte) & $00: 25: 45$ \\
\hline Processo Almoxarifado & Tempo \\
\hline Transformação de cartões em pedidos & $00: 13: 41$ \\
Separação de Material & $00: 41: 27$ \\
\hline
\end{tabular}

Fonte: Elaborado pelos autores (2019).

\subsection{Projeto do novo sistema}

Dados os objetivos levantados no estudo preliminar, obteve-se o desenho do novo sistema, o qual serviu de base tanto para a equipe de desenvolvimento elaborar o software, quanto aos líderes do projeto na aquisição do hardware necessário. O novo sistema foi pensado de forma a possibilitar aumento de eficiência e confiabilidade do processo. O mapeamento do novo sistema é apresentado por meio de um diagrama (Figura 3). O fluxo de materiais permanece equivalente ao cenário anterior, porém o fluxo de informações sofreu mudanças significativas. Os cartões Kanban foram substituídos por um sistema eletrônico composto de coletor de dados e códigos de barras. Os códigos de barras virão nas etiquetas das embalagens enviadas pelos fornecedores, sendo que cada caixa terá um código único, com informações de identificação do item, lote e data de produção. Com a ausência dos cartões Kanban o processo do Almoxarifado é o mais impactado positivamente, seguido da Logística e Montagem. 
Kanban Eletrônico para otimização de processos internos e externos da cadeia de suprimentos: aplicação em uma empresa do setor

automotivo

Figura 3- Diagrama do sistema futuro.

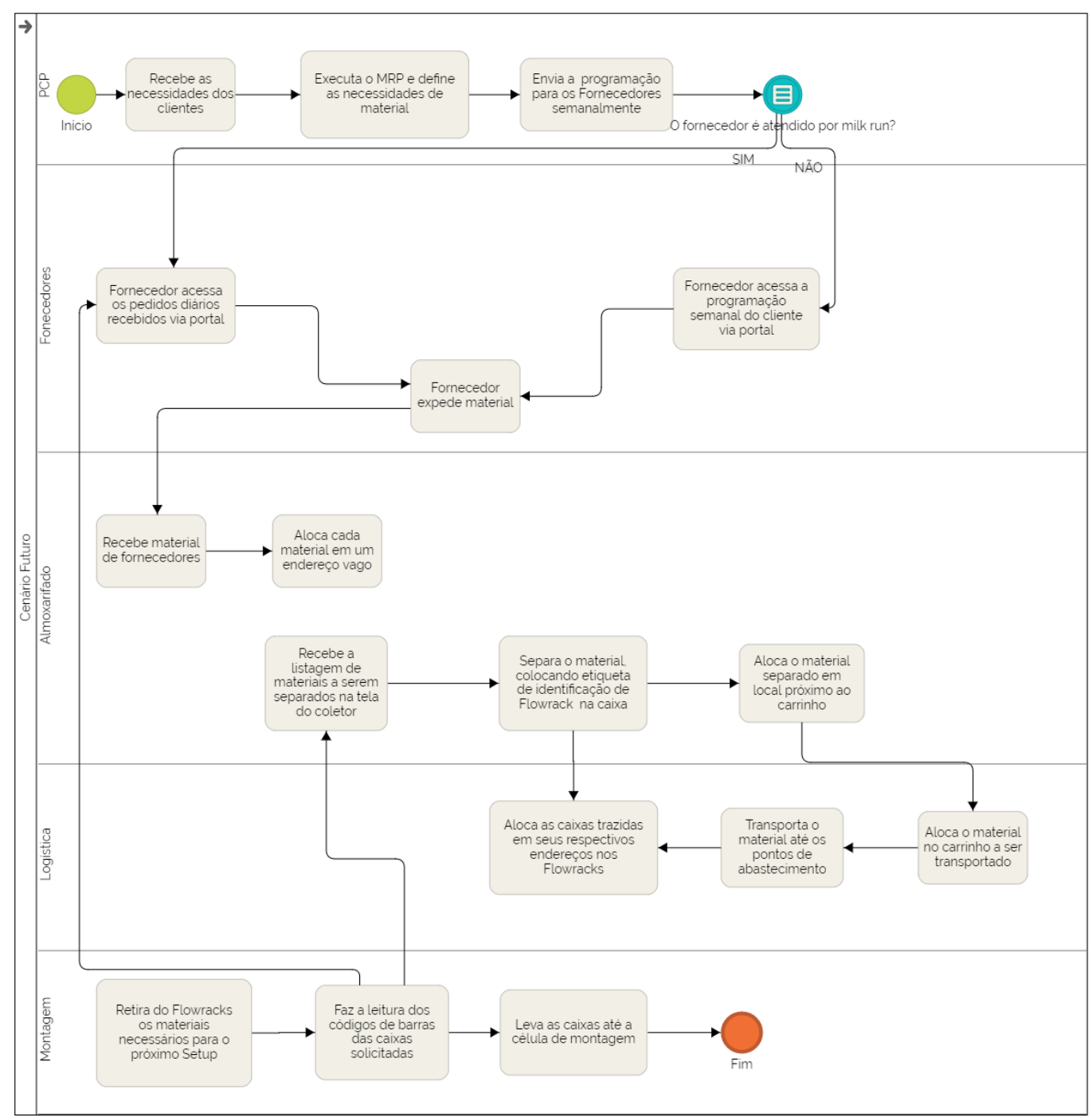

Fonte: Elaborado pelos autores (2019).

No momento em que o abastecedor da Montagem buscar o material para o próximo setup no flowrack, é feita a leitura dos códigos das caixas separadas. Para a execução desta atividade o colaborador acessa o sistema e inicia o procedimento de leitura dos códigos. Cada código pode ser lido uma única vez, de maneira a evitar a duplicidade das informações. Todas as suas solicitações de material são convertidas no sistema em pedidos do tipo "Picking List" ou "RM", dependendo do material.

Estes pedidos aparecem no sistema para o coletor de dados do Almoxarifado, ordenados de acordo com a lógica First In, First Out (FIFO). Na tela do sistema do Almoxarifado, há o 
Kanban Eletrônico para otimização de processos internos e externos da cadeia de suprimentos: aplicação em uma empresa do setor automotivo

indicativo do item solicitado, o endereço no armazém e o endereço de destino do material, o qual se refere ao código do flowrack. Porém, caso o material não esteja disponível no Almoxarifado, ele não fica visível na tela do coletor. Além disto, as solicitações de materiais produzidos por fornecedores nacionais atendidos pelo Milk Run também são convertidas em pedidos e disponibilizadas imediatamente via portal, de forma que os itens possam ser supridos na próxima rota de entrega, no dia seguinte ou dois dias depois.

O processo no Almoxarifado fica simplificado em relação ao anterior, uma vez que, com as informações disponíveis no coletor, o auxiliar de Almoxarifado deve apenas separar os materiais e o analista de Almoxarifado confirma a separação do material fazendo a leitura do endereço e da caixa. Para a Logística, o processo sofre pequenas modificações. A sua responsabilidade durante a rota é a de abastecer os flowracks, sem a necessidade de retornar os cartões, nem administrá-los. Além disto, observam-se melhorias na gestão visual, visto que a indicação de destino do material é colada no exterior da caixa.

\subsection{Implantação do Sistema}

Devido a restrições do projeto, como a necessidade de aquisição de um grande número de coletores de dados e adequação de $100 \%$ das embalagens de fornecedores com códigos de barras, a data de entrega da solução final acabou sendo estendida em relação à previsão original. Todavia, com a finalidade de acelerar a implantação do sistema de Kanban Eletrônico e de forma que a empresa pudesse se beneficiar imediatamente da automação do processo, foi decidido iniciar a implantação de uma solução transitória intermediária.

Para a implantação de tal solução intermediária, foram adquiridos cinco coletores de dados, um para o auxiliar logístico e os demais para uso dos auxiliares de Almoxarifado. $\mathrm{O}$ desenvolvimento de software também foi simplificado, bem como a necessidade de treinamento de pessoal.

A solução intermediária mudou a forma como se realiza a leitura das caixas solicitadas, uma vez que foram alocadas etiquetas contendo os códigos de barras nos próprios flowracks, nos endereços dedicados de cada item. A etiqueta contém o código de identificação do material, a descrição do item e o número de caixas que devem ser armazenadas naquele endereço. Porém, este número é calculado da mesma forma que o número de cartões era dimensionado no cenário 
Kanban Eletrônico para otimização de processos internos e externos da cadeia de suprimentos: aplicação em uma empresa do setor automotivo

antigo, visto que a informação continua demorando até duas horas para chegar ao Almoxarifado, tempo este que se refere ao período entre rotas, para então o material ser separado.

As demais etapas do processo no Almoxarifado ocorreram da maneira proposta anteriormente. Porém, quanto ao Kanban Eletrônico externo, foi decidido que seria implantado juntamente com a solução completa.

\section{DISCUSSÃO}

A implantação do sistema intermediário permitiu que se solucionassem alguns problemas identificados no antigo sistema de abastecimento. A extinção dos cartões Kanban permitiu diminuir o retrabalho da Logística com a reposição destes, o que auxilia na operacionalização mais eficiente do JIT, conforme indica Slack (2002). Além disto, todas as transações passaram a ter um registro no sistema, aumentando a confiabilidade do processo. Para tangibilizar o impacto do novo processo de abastecimento, foi realizada nova contagem dos tempos nos setores de Almoxarifado e Logística. Os resultados encontram-se na Tabela 2.

Tabela 2 - Tempos do sistema implantado

\begin{tabular}{lc}
\hline Processo Logística & Tempo \\
\hline Abastecimento do Flowrack & $00: 15: 28$ \\
Solicitação de material com o coletor de dados & $00: 07: 49$ \\
Tempo total da rota (incluindo o transporte) & $00: 32: 51$ \\
\hline Processo Almoxarifado & Tempo \\
\hline Senaracão de Material & $00: 36: 13$
\end{tabular}

Fonte: Elaborado pelos autores (2019).

Os maiores ganhos foram percebidos no Almoxarifado, onde o tempo de operação foi reduzido (aproximadamente, 20 minutos, ou três horas por dia), aumentando a velocidade da informação e aumentando a confiabilidade do processo. Este resultado conversa diretamente com os resultados de Kouri et al. (2008) me função dos benefícios da implantação do Kanban eletrônico. Em contrapartida, a operação da Logística teve um incremento de tempo de aproximadamente sete minutos, quase uma hora por dia. Além disto, o processo não foi completamente automatizado, visto que depende do operador para analisar quais materiais precisam ser solicitados. 
Kanban Eletrônico para otimização de processos internos e externos da cadeia de suprimentos: aplicação em uma empresa do setor

automotivo

Para verificar a aceitação e compreensão do novo sistema por parte dos usuários, foram realizadas entrevistas semi estruturadas com 11 operadores, tanto da Logística quanto do Almoxarifado e Montagem. Dez consideraram o impacto da implantação positivo nas suas respectivas áreas, sendo que um (colaborador da Montagem) considerou que não houve impacto significativo em seu trabalho.

Três operadores da Logística reportaram que, apesar do tempo de operação ter aumentado, consideram o impacto positivo, pois não precisam mais administrar cartões e possuem maior controle e entendimento sobre quais materiais estão sendo solicitados. Tais percepções fortalecem os achados de Bowersox et al. (2009), no que tange à facilidade troca de informações logísticas entre os membros da cadeia. O único aspecto negativo que mencionaram foi em relação às falhas de conectividade com a internet que eventualmente geram perdas e retrabalhos. Isto é um ponto de atenção, pois enquanto a literatura aponta os benefícios que o sistema aporta, é preponderante garantir que a solução funcione.

Os operadores do Almoxarifado identificaram que os seguintes aspectos melhoraram: aumento da produtividade - previsto na literatura por Ross (2011), a redução do uso de papel (destaque conferido por Ross (2011), Stair (1998) e Kouri et al. (2008)) e o aumento da confiabilidade - aspecto destacado por Perottoni (2001). Entre as dificuldades enfrentadas, sobressaíram a dificuldade de adaptação ao novo sistema e as falhas que ocorreram em consequência de problemas de conexão com a internet.

Para a Montagem, quatro dos cinco abastecedores valorizaram o fato de não precisarem mais controlar os cartões Kanban e que rupturas no abastecimento se tornaram mais esporádicas, o que aumentou a confiabilidade no sistema. Entre as dificuldades relataram que durante a adaptação ocorreram algumas falhas no abastecimento de alguns materiais no local incorreto e colocação de materiais em excesso nos Flowracks.

Avaliando os resultados, verifica-se que a implantação do sistema aumentou a eficiência do processo, apesar da discreta redução de tempo total percebida. Porém, o sistema intermediário ainda possui chances de incorrer em rupturas de abastecimento. Acredita-se que com a implantação de maneira completa do sistema proposto, seja possível perceber resultados mais significativos, principalmente no que se refere a redução de estoque intermediário, consequência da diminuição do tempo de envio dos pedidos ao Almoxarifado. A frequência das 
Kanban Eletrônico para otimização de processos internos e externos da cadeia de suprimentos: aplicação em uma empresa do setor automotivo

rotas de abastecimento permanecerá sendo a cada duas horas, mas, os pedidos chegarão instantaneamente no Almoxarifado para serem separados, e não mais em até duas horas. Desta forma, levando em consideração que o auxiliar de Almoxarifado poderia separar materiais cujos pedidos chegassem até dez minutos antes da rota do rebocador, e que este levasse até vinte minutos para abastecer o último flowrack da rota, os supermercados poderiam ser dimensionados para atender duas horas e trinta minutos de produção. Com essa diminuição, o estoque intermediário sofreria uma redução significativa, estimada em $24 \%$. Isto está consoante com os resultados de Kouri et al (2011) em relação ao aumento da eficiência. Esta estimativa foi feita, redimensionando-se os flowracks para que atendam a duas horas e trinta minutos de abastecimento, ao invés de quatro horas. Assim, transformando-se para valor monetário, prevêse uma redução de 72 mil reais de estoque intermediário.

Portanto, conclui-se que com a implantação do sistema intermediário contribui positivamente para a empresa. Como a solução está dividida em dois momentos, de maneira imediata observa-se que os benefícios alcançados vão ao encontro da literatura ao dar conta da diminuição do inventário, extinção dos erros e ajustes de estoque, confirmando os resultados de aumento de confiabilidade de Kouri et al. (2011) e os resultados de Laudon e Laudon (2012), em relação ao aumento do valor criado pela empresa. Em um segundo momento, com a solução completa, pode-se extrapolar os ganhos e verifica-los ainda mais robustos: dado que a solução permitirá a automatização de informações e a tomada de decisões estratégicas, ganhos com aumento da capacidade de lidar com sistemas mais complexos (maior mix de produção) de maneira eficiente e com menores custos.

\section{CONCLUSÃO}

Uma efetiva gestão da cadeia de suprimentos, integrando tanto informações quanto o fluxo de materiais, representa uma importante forma de garantir vantagem competitiva às empresas. Contudo, para viabilizar esta integração, o uso de SI é um requisito. A presente pesquisa propôs, implantou e avaliou criticamente uma solução de Kanban Eletrônico em uma indústria do setor automotivo.

A partir da solução simplificada do sistema foi possível identificar alguns pontos positivos da automatização do processo. Apesar das limitações financeiras e temporais que 
Kanban Eletrônico para otimização de processos internos e externos da cadeia de suprimentos: aplicação em uma empresa do setor automotivo

impediram a implantação completa do sistema, ainda assim, resultados discutidos na literatura foram visualizados: aumento da eficiência e tempos de operação, aumento da confiabilidade do processo impactaram positivamente a estrutura interna e externa ao integrar informações com os fornecedores. Evidente que os resultados estão setorizados, sendo o setor de Almoxarifado o setor em que se vislumbra e mensura ganhos no processo tanto no fator tempo quanto em relação à confiabilidade. Porém, o impacto para as demais áreas foi sutil ou negativo, como para a Logística, que teve sua operação ainda mais dificultada. Isto é, para alcançar os objetivos inicialmente traçados, é necessário a implantação da proposição do sistema completo, cujos resultados esperados são positivos. Indica-se que é importante, que estes sistemas contem com possíveis sistemas redundantes de suporte para garantir seu funcionamento.

Para futuros trabalhos acadêmicos na área, sugere-se uma investigação dos benefícios da integração com fornecedores por meio do Kanban Eletrônico no setor automotivo a partir da completa implantação do sistema, verificando os ganhos financeiros identificados.

\section{Referências}

ABINAJM FILHO, J.; DE FARIA, A. C., DA SILVEIRA, M. A. P. Efeito chicote na indústria automotiva brasileira. In: SIMPÓSIO DE ADMINISTRAÇÃO DA PRODUÇÃO, LOGÍSTICA E OPERAÇÕES INTERNACIONAIS, 15, 2012, São Paulo. Anais... SIMPOI. São Paulo: $\quad 2012 . \quad$ FGV, Disponível em: http://www.simpoi.fgvsp.br/arquivo/2012/artigos/E2012_T00108_PCN18299.pdf. Acesso em: 09 de Abril de 2016.

AMANN, P. J. Implantação de um kanban eletrônico em uma montadora de produtos de linha branca. Dissertação. 105f. 2009. (Mestrado em Engenharia de Produção) - Universidade Federal de São Carlos, São Carlos, 2009.

BICKMAN, L.; ROG, D.J. The Sage handbook of applied social research methods. Thousand Oaks: Sage Publications, 2008.

BOWERSOX, D.J., CLOSS, D.J., COOPER, M.B. Supply Chain Logistics Management. 3 ed. New York: McGraw-Hill/Irwin, 2009.

BRANSKI, R. M.; LAURINDO, F. J. B. Tecnologia da informação e integração das redes logísticas. Gestão \& Produção, v. 20, n.2, 2013.

CHIASSON, M.; GERMONPREZ, M.; MATHIASSEN, L. Pluralist action research: a review of the information systems literature. Information Systems Journal, v. 19, n. 1, p. 31-54, 2009. 
Kanban Eletrônico para otimização de processos internos e externos da cadeia de suprimentos: aplicação em uma empresa do setor

automotivo

COELHO, L.C.; FOLLMANN, N.; RODRIGUEZ, C.M.T. O impacto do compartilhamento de informações na redução do efeito chicote na cadeia de abastecimento. Gestão \& Produção, v. 16, n.4, p. 71-583, 2009.

CSCMP. Supply Chain Management Terms and Glossary. 2013. Disponível em: https://cscmp.org/sites/default/files/user_uploads/resources/downloads/glossary-2013.pdf Acesso em: 12 de Abril de 2016.

DEVIKA, K.; JAFARIAN, A.; HASSANZADEH, A.; KHODAVERDI, R. Optimizing of bullwhip effect and net stock amplification in three-echelon supply chains using evolutionary multi-objective metaheuristics. Annals Of Operations Research, v. 242, n. 2, p.457-487, 2014.

FIALHO, R. C. N. Tecnologia de informação como vantagem competitiva na cadeia de suprimento da FIAT automóveis. Dissertação. 124f. 2001. (Mestrado em Engenharia de Produção) - Universidade Federal de Santa Catarina, Florianópolis, 2001.

GIL, A. C. Como Elaborar Projetos de Pesquisa. São Paulo: Atlas, 2012.

GUNASEKARAN, A.; NGAI, E. W. Information systems in supply chain integration and management. European Journal of Operational Research, v. 159, n.2, p. 269-295, 2004.

HOFMANN, E.; RÜSCH, M. Industry 4.0 and the current status as well as future prospects on logistics. Computers in Industry, p. 23-34, 2017.

JAIPURIA, S.; MAHAPATRA, S.S. An Improved Demand Forecasting Method To Reduce Bullwhip Effect In Supply Chains. Expert Systems with Applications, v. 41, n. 5, p.23952408, 2014.

KOURI, I.A.; SALMIMAA, T.J.; VILPOLA. The Principles and Planning Process of An Electronic Kanban System. In: SOBH, T., ELLEITHY, K., MAHMOOD, A.; KARIM, M. A. Novel Algorithms and Techniques in Telecommunications, Automation and Industrial Electronics. London: Springer Science \& Business Media, 2008. p. 99-104.

LAMBERT, D. M.; COOPER, M. C. Issues in supply chain management. Industrial Marketing Management, v. 29, n.1, p. 65-83, 2000.

LAUDON, K.C., LAUDON, J.P. Management Information Systems. 12 ed. Prentice Hall, 2012.

LAUDON, K. C.; LAUDON J. P. Sistemas de informação gerenciais. 11. ed. São Paulo: Pearson Education do Brasil, 2014.

LAURINDO, F. J. B.; SHIMIZU, T.; CARVALHO, M. M. D.; RABECHINI JR, R. O papel da tecnologia da informação (TI) na estratégia das organizações. Gestão \& Produção, v. 8, n.2, p.160-179, 2001.

LEE, I.; LEE, K. The Internet of things (IoT): applications, investments, and challenges for enterprises. Business Horizons, Blomington, v. 58, n. 4, p. 431-440, 2015. 
Kanban Eletrônico para otimização de processos internos e externos da cadeia de suprimentos: aplicação em uma empresa do setor

automotivo

LEE, H.C.; PADMANABHAN, V.; WHANG, S. Comments on "Information Distortion in a Supply Chain: the bullwhip effect". Management Science, v.50, n.12, p.1887-1893, 2004.

MAÇADA, A. C. G.; FELDENS, L. F.; SANTOS, A. M. Impacto da tecnologia da informação na gestão das cadeias de suprimentos-um estudo de casos múltiplos. Gestão \& Produção, v. 14, n.1, p. 1-12, 2007.

MELlO, C. H. P.; TURRIONI, J. B.; XAVIER, A. F.; CAMPOS, D. F. Pesquisa-ação na engenharia de produção: proposta de estruturação para sua condução. Revista Produção, v. 22, n.1, p. 1-13, 2012.

MESQUITA, M. D.; CASTRO, R. D. Análise das práticas de planejamento e controle da produção em fornecedores da cadeia automotiva brasileira. Gestão e Produção, v.15, n.1, 33 42, 2008.

MIRANDA, M. G. D.; RESENDE, A. C. A. Sobre a pesquisa-ação na educação e as armadilhas do praticismo. Revista Brasileira de Educação, v.11, n.33, p. 511-518, 2006.

O'BRIEN, J.A.; MARAKAS, G.M. Management Information Systems. 10 ed. McGraw-Hill Education, 2010.

PEROTTONI, R.; OLIVEIRA, M.; LUCIANO, E.M.; FREITAS, H. Sistemas de informações: um estudo comparativo das características tradicionais às atuais. Universidade Federal do Rio Grande do Sul, v.7, n. 3, 2001. Disponível em: http://read.adm.ufrgs.br. Acesso em: 09 de Abril de 2016.

PRAJOGO, D.; OLHAGER, J. Supply chain integration and performance: The effects of longterm relationships, information technology and sharing, and logistics integration. International Journal of Production Economics, v.135, n.1, p. 514-522, 2012.

REZENDE, D.A.; ABREU, A.F. Tecnologia da Informação aplicada a Sistemas de Informação Empresariais: o papel estratégico da informação e dos sistemas de informação nas empresas. São Paulo: Atlas, 2006.

ROSS, D.F. Introduction to Supply Chain Management Technologies. 2 ed. CRCPress,2011.

SLACK, N.; CHAMBERS, S.; JOHNSTON, R. Administração da Produção. São Paulo: Atlas, 2002.

SIRIKASEMSUK, K.; LUONG, H. T. Measure of bullwhip effect in supply chains with firstorder bivariate vector autoregression time-series demand model. Computers \& Operations Research, v. 78, p.59-79, 2017.

STAIR, R.M. Princípios de Sistemas de Informação: Uma abordagem gerencial. Rio de Janeiro: LTC, 1998.

WANG, X., DISNEY, S. M. The bullwhip effect: Progress, trends and directions. European Journal of Operational Research, v. 250, n.3, p. 691-701, 2016. 